\title{
VARIACIÓN MORFOLÓGICA DE TRES ESPECIES DE CURUBAS (Passiflora tripartita var. mollissima, P. tarminiana y P. mixta) Y SUS HÍBRIDOS EN EL VALLE DEL CAUCA (COLOMBIA) $)^{1}$
}

\author{
SOPHIE PRIMOT², GEO COPPENS D’EECKENBRUGGE³, VINCENT RIOUX ${ }^{4}$, JOHN ALBEIRO OCAMPO PÉREZ \\ FRANÇOIS GARCIN ${ }^{6}$
}

\begin{abstract}
RESUMEN - Se estudió la variación morfológica entre ocho accesiones de las tres principales especies de curubas cultivadas y silvestres del Valle del Cauca, Passiflora tripartita var. mollissima (curuba de Castilla), Passiflora tarminiana (curuba india) y Passiflora mixta (curuba de monte) y 11 de sus híbridos, usando el análisis de componentes principales y el método de clasificación del vecino más próximo en 105 caracteres cualitativos y cuantitativos. Siete componentes principales explican $84 \%$ de la varianza total. Las clasificaciones sobre los caracteres cualitativos y cuantitativos muestran una clara agrupación por especie. Dentro de $P$. mixta, se distinguen un tipo poco pubescente, representativo de las plantas silvestres más comunes, y un tipo muy pubescente, con caracteres de domesticación como frutos amarillentos de pulpa colorida, y con una mayor variación morfológica. La clasificación de estos últimos individuos sugiere una introgresión entre P. mixta y Passiflora tripartita var. mollissima. Los híbridos ocupan una posición intermedia entre las especies parentales, pero se diferencian claramente según la dirección del cruzamiento, revelando un efecto maternal sobre la herencia de los caracteres vegetativos y florales. Los primeros análisis del fruto muestran características intermedias en cuanto a forma, color y tolerancia a la antracnosis.
\end{abstract}

Palabras claves: caracterización morfológica, diversidad genética, premejoramiento, antracnosis.

\section{MORPHOLOGICAL VARIATION OF THREE BANANA PASSION FRUIT SPECIES (PASSIFLORA TRIPARTITA VAR. MOLLISSIMA, P. TARMINIANA AND P. MIXTA) AND THEIR HYBRIDS IN THE CAUCA VALLEY (COLOMBIA)}

\begin{abstract}
Morphological variation was studied in eight accessions from the three most common cultivated and wild species of banana passion fruit in the Cauca Valley, Passiflora tripartita var. mollissima (curuba de Castilla), P. tarminiana (curuba india) and P. mixta (curuba de monte), and 11 of their hybrids, using the principal component analysis and neighbor joining cluster analysis on 105 qualitative and quantitative traits. The seven principal components explain $84 \%$ of the total variance. The principal component and cluster analyses clearly show the groups accessions by species. Two subgroups are distinguished within P. mixta, one with little pubescence, representative of the most common wild type, and a very pubescent one, with characters associated with domestication, such as yellowish fruit and colored pulp, and a wider morphological variation. Their position in the different classification strongly suggests a spontaneous introgression between P. mixta and Passiflora tripartita var. mollissima. The hybrids take an intermediate position between the parental species, but closer to the maternal parent, revealing a maternal effect on vegetative and floral traits. The first analyses of their fruit show intermediate characteristics in shape, color, and tolerance to anthracnose.

Index terms: morphological characterization, genetic diversity, germplasm enhancement, anthracnose.
\end{abstract}

\section{INTRODUCCIÓN}

Las curubas pertenecen al subgénero Tacsonia del género Passiflora (Passifloraceae), el cual cuenta con 21 especies en Colombia, según la lista publicada por Hernández \& Bernal (2000), dos de ellas ampliamente cultivadas a nivel comercial o del huerto casero. La más importante es P. tripartita var. mollissima Holm-Nielsen \& Møller Jørgensen o curuba de Castilla (anteriormente conocida como P. mollissima (Kunth) Bailey), cuyo cultivo comercial se inició a fines de los años 50 en el altiplano cundiboyacense (Jaramillo, 1957, 1958), alcanzando rápidamente una extensión de aproximadamente 2500 ha en el país. Sus características organolépticas la hacen clasificar entre las mejores pasifloras comestibles. La segunda en importancia, P. tarminiana Coppens $\&$ Barney, curuba india o curuba ecuatoriana, ha sido tradicionalmente cultivada en huertos caseros, pero un número creciente de productores la está explotando a nivel comercial por sus características de productividad y rusticidad (Campos, 2001). Es particularmente interesante por su resistencia a la antracnosis (Colletotrichum gloeosporioides (Penzig) Penzig \& Saccardo), enfermedad que afecta gravemente la calidad de los frutos y la productividad de los curubales de las zonas productoras del Valle del Cauca, donde muchos cultivos de curuba de Castilla han sido abandonados o sustituidos por la curuba india. Como parece común en el subgénero (Escobar, 1981), las dos especies son autocompatibles y se hibridizan fácilmente. Sus híbridos, espontáneos o controlados, parecen plenamente fértiles. Sin embargo, el interés de la curuba india para el mejoramiento de la curuba de Castilla ha sido opacado por la incertidumbre sobre su posición taxonómica, ya que su descripción botánica formal sólo se dio recientemente (Coppens d'Eeckenbrugge et al., 2001).

P. mixta L.f., o curuba de monte, constituye otro recurso genético para considerar en el mejoramiento de la curuba de Castilla, por sus evidentes afinidades morfológicas con esta especie, por su alta diversidad y por las características de resistencia que podría mostrar esta especie silvestre, muy común desde Venezuela hasta Perú, encima de 2000 m. Es ocasionalmente colectada o aún cultivada en Venezuela. Cruzada con P. tripartita var. mollissima, produce híbridos fértiles (Escobar, 1981; Schoeniger, 1986).

Estudios anteriores de la diversidad genética del subgénero Tacsonia se han apoyado en la caracterización por medio de marcadores morfológicos (Villacis et al., 1998), isoenzimáticos (Segura et al., 2003b) y AFLP (Segura et al., 2003a). El primer estudio mostró una relación estrecha entre $P$. tripartita var. mollissima y $P$. mixta, la cual fue confirmada con el estudio de la variación isoenzimática, que sólo permitió separar claramente P. tarminiana de las dos otras. Los marcadores AFLP permitieron separar las tres especies, aunque confirmaran su estrecha relación, con distancias inferiores en comparación con otras especies del subgénero (Segura et al., 2003a). Los estudios más generales de Fajardo et al. (1998) y Sánchez

\footnotetext{
${ }^{1}$ (Trabalho 165/2004). Recebido: 03/12/2004. Aceito para publicação: 18/11/2005.

${ }^{2}$ Eng. Agr., MSc., pesquisadora, INRA-SAD, Domaine du Joly, Avenue Louis Buffet, 88500 Mirecourt, França. T. 33(0)3 83 39 40 41. sprimot@hotmail.com.

${ }^{3}$ Eng. Agr. PhD, pesquisador, CIRAD, UPR 'Gestion des Ressources Génétiques et Dynamiques Sociales', Campus CNRS/CEFE, 1919 Route de Mende, 34293

Montpellier, França. T. 33(0)4 676132 99. geo.coppens@cirad.fr.

${ }^{4}$ Biólogo, MSc. rioux_vincent@yahoo.fr.

${ }_{5}^{5}$ Eng. Agr., MSc, pesquisador, IPGRI, c/o CIAT, A.A. 6713, Cali, Colombia. T 57(0)2 44500 29. john.ocampo@voila.fr.

${ }^{6}$ Biólogo, MSc. garcin.fr@free.fr.
} 
TABLA 1 - Lista de las accesiones utilizadas.

\begin{tabular}{|c|c|c|c|}
\hline ESPECIE & CODIGO & $\mathrm{N}^{\circ}$ DE PLANTAS & ORIGEN \\
\hline P. tarminiana & T.tito & 3 & Valle del Cauca \\
\hline P. tripartita var. mollissima & mo.AG & 3 & Valle del Cauca \\
\hline P. tripartita var. mollissima & mo.FA & 2 & Valle del Cauca \\
\hline P. mixta & mx.Tito & 3 & Valle del Cauca \\
\hline P. mixta & mx.Toño & 1 & Valle del Cauca \\
\hline P. mixta & $\mathrm{mx} . \mathrm{cp}$ & 2 & Valle del Cauca \\
\hline P. mixta & mx.viv & 2 & Valle del Cauca \\
\hline P. mixta & mx.cami & 1 & Valle del Cauca \\
\hline P. mixta (mx.Tito) x P. tripartita var. mollissima & $\mathrm{M}^{*} \mathrm{C}$ & 4 & Valle del Cauca \\
\hline P. tarminiana $\mathrm{x}$ P. trip artita var. mollissima & $\mathrm{I} * \mathrm{C}$ & 4 & Valle del Cauca \\
\hline P. tripartita var. mollissima $\mathrm{x}$ P. tarminiana & $\mathrm{C}^{*} \mathrm{I}$ & 4 & Valle del Cauca \\
\hline
\end{tabular}

et al. (1999), con marcadores RAPDs y RFLP, permitieron separar P. tarminiana de P. tripartita var. mollissima, mostrando también una fuerte afinidad, pero no incluían accesiones de P. mixta.

Los marcadores moleculares permiten acceder directamente al soporte de la información genética, sin embargo no están siempre disponibles por problemas de costo, de disponibilidad de laboratorio o de técnicas adaptadas a las especies estudiadas. Al contrario, los marcadores morfológicos son de fácil acceso y su información es indispensable para los trabajos de mejoramiento, que no pueden basarse esencialmente en secuencias de ADN. La caracterización morfológica pretende mostrar atributos que diferencian o relacionan las plantas evaluadas. En el contexto más general del estudio de la diversidad genética de las curubas cultivadas, sus parientes silvestres y su sistema reproductivo, el presente trabajo fue enfocado en la exploración del potencial de las tres especies para el mejoramiento genético de las curubas cultivadas en el Valle del Cauca, con particular interés en las características pomológicas cualitativas y de resistencia/tolerancia a la antracnosis.

\section{MATERIALES Y MÉTODOS}

En la vereda Tenerife del municipio de El Cerrito (Valle del Cauca; $2600 \mathrm{~m}$ ), se llevó a cabo la caracterización morfológica en dos accesiones de $P$. tripartita var. mollissima, una de P. tarminiana, cinco de $P$. mixta y tres accesiones de sus híbridos, utilizando entre una y cuatro plantas por accesión (Tabla 1). Todas son oriundas de la zona del estudio. La accesión $\mathrm{mx}$. Tito fue establecida a partir de la semilla de una planta recuperada en estado silvestre por un productor que la instaló en su huerto. Los híbridos se obtuvieron cruzando las accesiones mo.AG y T.Tito para las hibridaciones entre $P$. tripartita var. mollissima y $P$. tarminiana, y mo.AG y mx. Tito para la hibridación entre $P$. tripartita var. mollissima y $P$. mixta, por emasculación de las flores usadas como hembra en la tarde anterior a la antesis y polinización controlada.

Se usó una lista preliminar de 105 descriptores desarrollada por CORPOICA, IPGRI y CIRAD, con la colaboración de instituciones de otros países andinos (lista no publicada). La lista incluye caracteres relacionados con los órganos vegetativos, florales y del fruto clasificados en cualitativos y cuantitativos (Tabla 2). Se estudiaron la distribución de las variables y las correlaciones entre ellas. Los datos cualitativos ordinales y los cuantitativos fueron sometidos al análisis de componentes principales (ACP) conservando los componentes con un valor propio mayor de uno y aplicándoles una rotación varimax normalizada (programa Statistica Versión 98). El análisis de clasificación fue realizado por el método del vecino más próximo (neighbor joining) usando distancias euclidianas sobre los valores de los componentes principales para las variables cuantitativas y distancias de Sokal y Michener calculadas sobre los datos crudos para las variables cualitativas (programa Winstat, CIRAD).

\section{RESULTADOS Y DISCUSION}

Las polinizaciones interespecíficas mostraron una fertilidad comparable a la de los cruces, con frutos cuajados llenos de semillas viables. No se detectó ningún problema en la germinación. Los híbridos se mostraron muy vigorosos y fértiles, con un fuerte desarrollo vegetativo, aunque la carga de frutos apareciera menor que en las especies parentales, particularmente en los híbridos P. mixta x P. tripartita var. mollissima. Sin embargo, sus frutos, como sus flores, están bien conformados, y contienen numerosas semillas. Como no se estableció la tasa de cuajamiento, no se puede sacar una conclusión definitiva al respeto. La facilidad de los cruzamientos entre P. tripartita var. mollissima, $P$. tarminiana y $P$. mixta, así como la fertilidad y el vigor vegetativo de los híbridos, confirman observaciones anteriores de híbridos espontáneos y experimentales en el subgénero Tacsonia (Escobar, 1981, 1985; Schoeniger, 1986).

La Tabla 3 presenta las principales características cualitativas de las diferentes especies y de los híbridos. Los representantes de $P$. mixta se dividen entre accesiones poco pubescentes, con frutos verdes de pulpa grisácea, del tipo silvestre más común en la zona (mx.viv y mx.cp), e individuos muy pubescentes, con frutos verdes amarillentos de pulpa anaranjada translúcida (mx.cami y mx.Tito). La accesión mx.viv presentó manchas blancas sintomáticas de ataques de oidio en su follaje. Se confirmó la alta susceptibilidad de P. tripartita var. mollissima a la antracnosis, mientras $P$. tarminiana no parece afectada por esta

TABLA 2 - Lista sintética de los descriptores morfológicos utilizados.

\begin{tabular}{|c|c|c|}
\hline ORGANO & CARACTERES CUALITATIVOS & CARACTERES CUANTITATIVOS \\
\hline Tallo & Forma, antocianina, pubescencia (ordinales) & Entrenudos \\
\hline Zarcillo & Antocianina & Longitud \\
\hline Estípula & Antocianina, pubescencia (ordinales), permanencia y forma & Dimensiones \\
\hline Hoja & $\begin{array}{l}\text { Antocianina y pubescencia (ordinales), polimorfismo, forma, } \\
\text { color, tipo, margen }\end{array}$ & $\begin{array}{l}\text { Longitud de lóbulos, ángulo entre nervaduras laterales, } \\
\text { distancia pecíolo-seno, densidad de dientes en el margen }\end{array}$ \\
\hline Pecíolo & Forma de los nectarios & Longitud, número y posición de nectarios \\
\hline Bractea & Forma, unión, permanencia & Dimensiones \\
\hline Flor & $\begin{array}{l}\text { Forma, colores y pubescencia de las partes, número de series de } \\
\text { filamentos, unión de sépalos y pétalos, antocianina y clorofila } \\
\text { sobre sépalos e hipantio }\end{array}$ & Número, orientación y dimensiones de las partes \\
\hline Fruto & $\begin{array}{l}\text { Pigmentación, pubescencia, forma, consistencia, síntomas de } \\
\text { antracnosis }\end{array}$ & \\
\hline
\end{tabular}

Rev. Bras. Frutic., Jaboticabal - SP, v. 27, n. 3, p. 467-471, Dezembro 2005 
TABLA 3 - Principales caracteres cualitativos polimórficos en las especies parentales y sus híbridos (colores de la corola según la tabla del Jardín Botánico de Kew).

\begin{tabular}{|c|c|c|c|c|c|c|}
\hline ORGANO & P. t. mollissima & P.tarminiana & P. mixta & C*I & $\mathbf{I} * \mathbf{C}$ & $\mathbf{M} * \mathbf{C}$ \\
\hline \multicolumn{7}{|l|}{ Tallo } \\
\hline Forma exterior & redondo/ estriado & estriado & estriado / angulado & /redondo estriado & $\begin{array}{l}\text { estriado/ } \\
\text { subangulado }\end{array}$ & estriado \\
\hline Pubescencia & aterciopelado & poco densa & glabro a aterciopelado & $\begin{array}{l}\text { poco densa/ } \\
\text { aterciopelado }\end{array}$ & aterciopelado & aterciopelado \\
\hline \multicolumn{7}{|l|}{ Estípulas } \\
\hline Duración & permanentes & decíduas & decíduas & $\begin{array}{l}\text { decíduas/ } \\
\text { permanentes }\end{array}$ & $\begin{array}{l}\text { decíduas/ } \\
\text { permanentes }\end{array}$ & permanentes \\
\hline \multicolumn{7}{|l|}{ Pecíolo } \\
\hline Pubescencia & aterciopelado & $\begin{array}{l}\text { poco densa/ } \\
\text { aterciopelado }\end{array}$ & $\begin{array}{l}\text { poco densa/ } \\
\text { aterciopelado }\end{array}$ & aterciopelado & $\begin{array}{l}\text { poco densa/ } \\
\text { aterciopelado }\end{array}$ & aterciopelado \\
\hline \multicolumn{7}{|l|}{ Hoja } \\
\hline Pubescencia haz & poco densa & $\begin{array}{l}\text { glabro/poco } \\
\text { densa }\end{array}$ & glabro a aterciopelado & $\begin{array}{l}\text { poco densa/ } \\
\text { aterciopelado }\end{array}$ & $\begin{array}{l}\text { poco densa/ } \\
\text { aterciopelado }\end{array}$ & aterciopelado \\
\hline Pubescencia envés & aterciopelado & poco densa & glabro/aterciopelado & aterciopelado & $\begin{array}{l}\text { poco densa/ } \\
\text { aterciopelado }\end{array}$ & aterciopelado \\
\hline \multicolumn{7}{|l|}{ Bráctea } \\
\hline Pubescencia & $\begin{array}{l}\text { poco densa/ } \\
\text { aterciopelada }\end{array}$ & poco densa & $\begin{array}{l}\text { glabro a } \\
\text { aterciopelado }\end{array}$ & aterciopelado & aterciopelado & aterciopelado \\
\hline \multicolumn{7}{|l|}{ Flor } \\
\hline Forma de la copa & campanulada & reflexa & campanulada & $\begin{array}{l}\text { campanulada/ } \\
\text { levemente reflexa }\end{array}$ & levemente reflexa & campanulada \\
\hline Orientación & péndula $\left(10-25^{\circ}\right)$ & péndula $\left(15-20^{\circ}\right)$ & Semi-erecta $\left(10-50^{\circ}\right)$ & péndula $\left(0-10^{\circ}\right)$ & péndula $\left(10-25^{\circ}\right)$ & péndula $\left(0-10^{\circ}\right)$ \\
\hline Color pétalos & $62 \mathrm{a}, 66 \mathrm{~d}, 68 \mathrm{~b}$ & $75 \mathrm{a}$ & $50 \mathrm{a}, 54 \mathrm{~b}, 55 \mathrm{a}$ & $68 \mathrm{~b}$ & $74 \mathrm{~b}$ & $55 \mathrm{~b}$ \\
\hline Color ovario & amarillo & $\begin{array}{l}\text { verde a amarillo } \\
\text { verdoso }\end{array}$ & amarillo verdoso/kaki & amarillo & amarillo/kaki & $\begin{array}{l}\text { amarillo a } \\
\text { amarillo verdoso }\end{array}$ \\
\hline Color estilos & rosado & amarillo & rosado & rosado & rosado & rosado \\
\hline $\begin{array}{l}\text { Distribución color } \\
\text { estilos }\end{array}$ & apice/uniforme & uniforme & uniforme/moteado & uniforme & uniforme/moteado & uniforme \\
\hline Fruto & & & & & & \\
\hline Forma & oblongo & fusiforme & elipsoide/fusiforme & fusiforme & fusiforme & elipsoide \\
\hline Color & amarillo & amarillo naranja & amarillo verde & amarillo claro & amarillo claro & amarillo claro \\
\hline $\begin{array}{l}\text { Manchas de } \\
\text { Antracnosis }\end{array}$ & $\begin{array}{l}\text { extensas con } \\
\text { deformaciones }\end{array}$ & indemne & algunas medias & $\begin{array}{l}\text { numerosas pero } \\
\text { muy pequeñas }\end{array}$ & $\begin{array}{l}\text { numerosas pero muy } \\
\text { pequeñas }\end{array}$ & $\begin{array}{l}\text { numerosas pero } \\
\text { pequeñas }\end{array}$ \\
\hline
\end{tabular}

enfermedad. Los frutos de P. mixta se ven moderadamente afectados. Los híbridos presentan una sensibilidad intermedia, con pecas pequeñas pero numerosas, que reducen la calidad externa de sus frutos.

La mayoría de las variables cuantitativas muestra una distribución continua clásica. Sin embargo, en ciertos casos, las diferencias entre las especies son tales que la distribución global llega a ser bimodal (diámetros del pedúnculo y orientación de la flor, diferenciando $P$. mixta, diámetro de la cámara nectarífera y longitud del hipantio, diferenciando $P$. tarminiana) o trimodal (longitud de las brácteas, diámetro del tubo floral).

En el ACP, se retuvieron siete componentes, los cuales explican $84 \%$ de la varianza total. Los componentes, obtenidos después de una rotación varimax normalizada, están relacionados respectivamente con (1) las dimensiones de la hoja, de las brácteas, de los pétalos, la longitud de los sépalos, el diámetro del tubo floral y la longitud del ovario, (2) la pubescencia de los diferentes órganos, la forma del tallo, el diámetro del pedúnculo y la orientación de la flor, (3) el tamaño de las estípulas, el ancho de los sépalos y la longitud de la cámara nectarífera, (4) la longitud de la flor (incluyendo hipantio, androginóforo y opérculo), (5) la separación de los lóbulos, (6) la longitud del peciolo, y (7) la longitud del ginóforo. La Figura 1 muestra la dispersión de los individuos en el plano principal, donde se separan claramente las tres especies parentales, con excepción de los individuos de P. mixta muy pubescentes (mx.cami y mx.Tito). Estos últimos ocupan una posición intermedia, cerca de los híbridos $\mathrm{M}^{*} \mathrm{C}$ de $P$. tripartita var. mollissima y $P$. mixta. Éstos se acercan más a su genitor materno, P. tripartita var. mollissima. Los otros híbridos, entre P. tripartita var. mollissima y P. tarminiana, también toman una posición intermedia, formando dos grupos según la dirección del cruzamiento, cada grupo acercándose a su genitor materno, más particularmente el grupo I*C.

Las diferencias interespecíficas en la distribución de los caracteres cualitativos y cuantitativos se reflejan también de manera muy coherente en las clasificaciones obtenidas con los dos tipos de variables. Tanto el dendrograma de la Figura 2, obtenido con los caracteres cualitativos, como el dendrograma obtenido a partir los componentes principales de la variación cuantitativa (Figura 3) separan claramente las dos especies de curubas cultivadas y la forma típica, poco pubescente, de P. mixta. En el dendrograma de la Figura 2, los híbridos interespecíficos toman posiciones intermedias, pero se acercan a la curuba de Castilla, con la excepción del híbrido I*C4. Las formas pubescentes de $P$. mixta muestran segregación, formando dos pequeños grupos cerca de P. tripartita var. mollissima y de sus descendientes híbridos. En el dendrograma obtenido a partir los siete componentes principales de la variación cuantitativa (Figura 3), los híbridos forman tres grupos mejor separados y más coherentes, uno incluyendo los híbridos $\mathrm{M}^{*} \mathrm{C}$, y dos incluyendo los híbridos de P. tripartita var. mollissima y $P$. tarminiana que se diferencian según la dirección del cruzamiento. Los híbridos $C^{*} \mathrm{I}$ se acercan un poco más a su genitor femenino. Tres de los cuatro individuos muy pubescentes de $P$. mixta se agrupan con los híbridos controlados de esta especie con P. tripartita var. mollissima, mientras el cuarto se une con los híbridos $C^{*} \mathrm{I}$.

La clara distinción entre los híbridos según la dirección del cruzamiento muestra un efecto maternal sobre la herencia de los caracteres vegetativos y florales, particularmente en los caracteres cuantitativos.

Es particularmente interesante la separación de P. mixta, entre un grupo uniforme de individuos poco pubescentes, típico de esta especie silvestre en la región, y un grupo segregante de individuos muy 


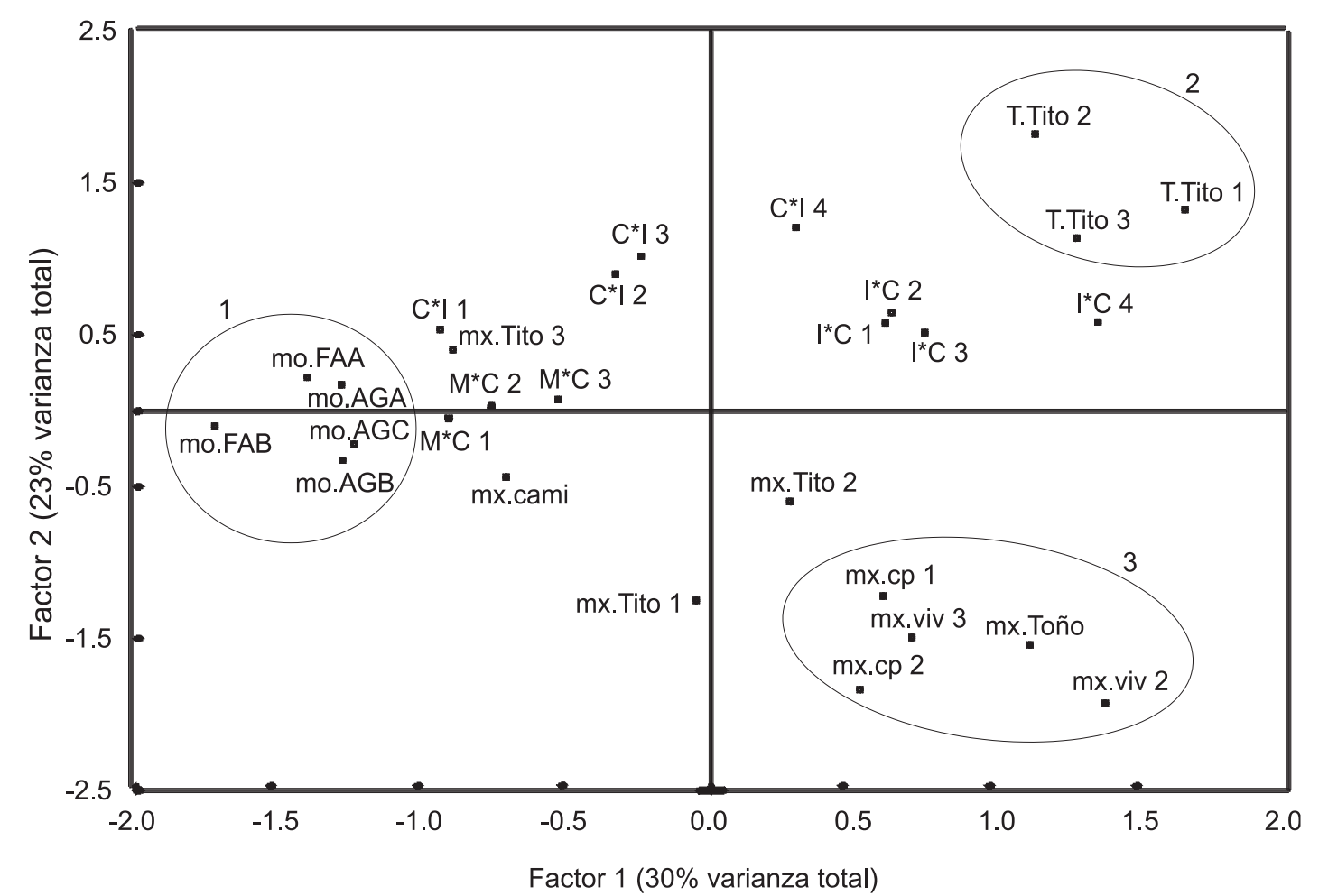

FIGURA 1- Dispersión de las accesiones en el plano principal (sin rotación varimax normalizada). Elipses: 1- P. tripartita var. mollissima, 2- P. tarminiana, 3- P. mixta poco pubescente.

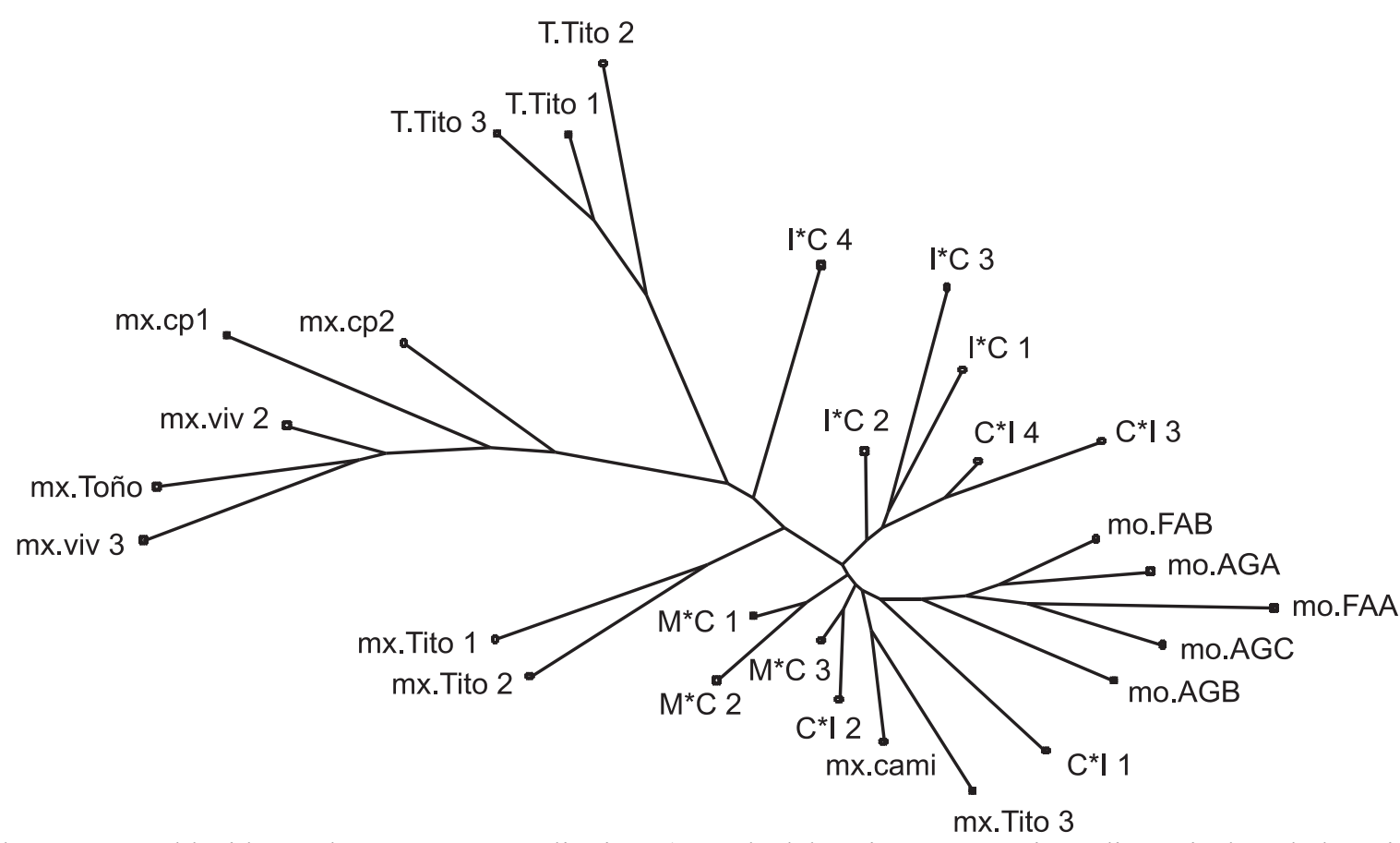

FIGURA 2 - Dendrograma establecido con los caracteres cualitativos (método del vecino más próximo, distancia de Sokal y Michener).

pubescentes mostrando caracteres de domesticación que los acercan a P. tripartita var. mollissima, como frutos maduros amarillo verdoso y pulpa anaranjada translúcida. Este segundo grupo incluye una planta silvestre (mx.cami), encontrada en una población con dos plantas del primer grupo, y los tres descendientes de la planta colectada por un productor, precisamente por sus características intermedias (accesión mx.Tito). En todos los análisis, estos cuatro individuos se acercan a los híbridos entre P. mixta y P. tripartita var. mollissima. Esta afinidad morfológica y la segregación observada indican que derivan de hibridaciones espontáneas entre las dos especies. Como fueron colectadas en estado silvestres, el pariente femenino debe ser $P$. mixta. Sin embargo, es muy verosímil que la hibridación recíproca ocurra de forma igualmente espontánea, ya que ciertos productores señalan que, entre las plántulas de curuba de Castilla producidas en sus viveros, tienen que descartar las que llaman vulgarmente "plantas macho", las cuales reconocen por sus hojas juveniles con lóbulos muy finos, parecidas a las hojas juveniles de $P$. mixta. Estas introgresiones explican las afinidades observadas con isoenzimas entre $P$. tripartita var. mollissima y P. mixta (Segura et al., 2003b).

La compatibilidad entre las tres especies estudiadas y la existencia de un flujo natural de genes a lo menos entre P. mixta y P. tripartita var. mollissima abre interesantes perspectivas para el mejoramiento de la curuba de Castilla. Sin embargo, la observación de manchas de antracnosis en los frutos de $P$. mixta y de los híbridos entre P. tripartita var. mollissima y P. tarminiana limita su potencial para cultivos comerciales. Además, indica que el carácter de resistencia a la antracnosis no es dominante, lo que dificultaría la obtención de cultivares resistentes de curuba de Castilla por introgresión controlada, cuestionando el interés de este método para resolver el principal problema de su cultivo en el Valle del Cauca. De hecho, aparecería un antagonismo entre los esfuerzos del fitomejorador para recuperar las características generales y organolépticas de $P$. tripartita var. mollissima, de un lado, y la necesidad de fijar genes de resistencia de P. tarminiana, en las mismas descendencias. 


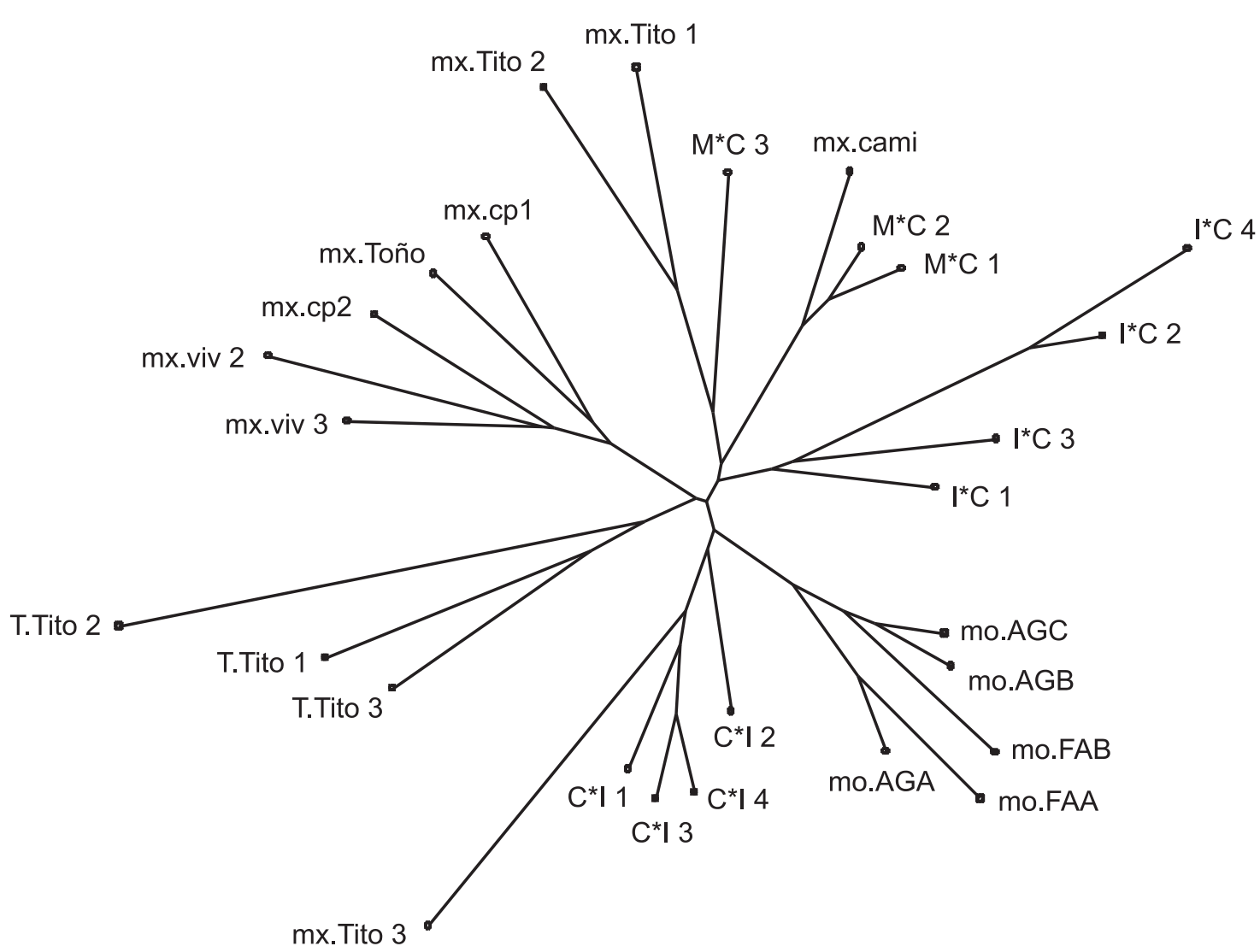

FIGURA 3 - Dendrograma obtenido con los componentes principales derivados de los caracteres cuantitativos (método del vecino más próximo, distancias euclidianas).

\section{CONCLUSIONES}

1. P. tarminiana y P. mixta mostraron alta compatibilidad interespecífica con $P$. tripartita var. mollissima. La primera no es afectada por la antracnosis mientras la segunda es menos afectada que la tercera. Los híbridos muestran una susceptibilidad intermedia pero suficiente para despreciar los frutos, presagiando dificultades para la introgresión de la resistencia de P. tarminiana en $P$. tripartita var. mollissima.

2. La caracterización morfológica permitió separar claramente las tres especies. Dentro de $P$. mixta, se distinguen un tipo representativo de las plantas silvestres más comunes, y un tipo con importante variación morfológica y rasgos de curuba de Castilla, indicando flujos de genes entre $P$. tripartita var. mollissima y $P$. mixta.

3. Los híbridos entre $P$. tripartita var. mollissima y $P$. tarminiana presentan una morfología intermedia entre sus genitores. Su clara diferenciación según la dirección del cruzamiento, evidencia un efecto maternal sobre la herencia de los caracteres morfológicos. Este efecto no se manifiesta sobre las características cualitativas de los frutos.

\section{AGRADECIMIENTOS}

Esta investigación fue parcialmente financiada por Colciencias a través del proyecto 1203-12-097-98 “conservación y utilización de los recursos genéticos de pasifloras".

\section{REFERENCIAS}

CAMPOS, T.J. La curuba: su cultivo. Bogotá: IICA, 2001. 87p. COPPENS d'EECKENBRUGGE, G; BARNEY, V.; MOLLER JØRGENSEN, P.; Mc DOUGAL, J. Passiflora tarminiana, a new cultivated species of Passiflora subgenus Tacsonia. Novon, St. Louis, v.11, p.8-15, 2001.
ESCOBAR, L. Experimentos preliminares en la hibridación de especies comestibles de Passiflora. Actualidades Biológicas, Lisboa, v.10, p.103-111,1981.

ESCOBAR, L. Biología reproductiva de Passiflora manicata e hibridación con la curuba, Passiflora mollissima. Actualidades Biológicas,Lisboa, v.14, p.111-121, 1985.

FAJARDO, D.; ANGEL, F.; GRUM, M.; TOHMÉ, J.; LOBO, M.; ROCA, W.M.; SÁNCHEZ, I. Genetic variation analysis of the genus Passiflora L. using RAPD markers. Euphytica, Dordrecht, 101, p.341-347, 1998.

HERNÁNDEZ, A.; BERNAL, R. Lista de especies de Passifloraceae de Colombia. Biota Colombiana, Bogotá, v.1, p.320-335, 2000.

JARAMILLO, A. Primeros resultados de un ensayo sobre el cultivo de la curuba (Passiflora spp.). Agricultura Tropical, Bogotá, v.13, p.301-308, 1957.

JARAMILLO, A. El cultivo de la curuba. Agricultura Tropical, Bogotá, v.14, p.712-717, 1958.

SÁNCHEZ, I.; ANGEL, F.; GRUM, M.; DUQUE, M.C.; LOBO, M.; TOHME, J.; ROCA, W. Variability of chloroplast DNA in the genus Passiflora L. Euphytica, Dordrecht, v.106,15-26, 1999.

SCHOENIGER, G. La curuba: técnicas para el mejoramiento de su cultivo. Bogotá: Ed. Guadalupe, 1986. 256p.

SEGURA, S.D.; COPPENS d'EECKENBRUGGE, G.; BOHÓRQUEZ,A.; OLLITRAULT, P.; TOHMÉ, J. An AFLP diversity study of the genus Passiflora focusing on subgenus Tacsonia.. Genetic Resources and Crop Evolution, Holanda, v.49, p.111-123, 2003 a.

SEGURA, S.D.; COPPENS d'EECKENBRUGGE, G.; OCAMPO, C. H.; OLLITRAULT, P. Isozyme variation in Passiflora subgenera Tacsonia and Manicata. Relationships between cultivated and wild species. Genetic Resources and Crop Evolution, Holanda, v.50, p.417-427, 2003b.

VILLACÍS, L.A.; VEGA, J.; GRUM, M.; COPPENS d'EECKENBRUGGE, G. Morphological characterization of Andean passifloras (Passiflora spp.) from Ecuador. Plant Genetic Resources Newsletter, Roma, v.115, p.51-55, 1998. 